\title{
Exploring the Effects of Installation Geometry in High-Lift Propeller Systems
}

\author{
Xiaofan Fei* \\ NASA Langley Research Center, Hampton, VA, 23681, USA \\ Brian J. German ${ }^{\dagger}$ \\ Georgia Institute of Technology, Atlanta, GA, 30332, USA \\ Michael D. Patterson \\ NASA Langley Research Center, Hampton, VA, 23681, USA
}

\begin{abstract}
A high-lift propeller system is a distributed electric propulsion technology which dedicates an array of wing-mounted tractor propellers to actively augment wing lift during takeoff and landing. This paper describes the results of a wind tunnel experiment dedicated to investigating the effects of high-lift propeller installation geometry on lift generation. Variables investigated include propeller height, offset, and inclination. Results show that propeller height is the most critical variable and that the height for maximum lift depends highly on the angle of attack and flap deflection. In addition, a relationship between optimal propeller height and the wing's unblown lift coefficient is discovered.
\end{abstract}

\section{Nomenclature}

$\begin{array}{ll}\alpha_{w} & =\text { wing angle of attack (corrected) } \\ \alpha_{w, \text { input }} & =\text { input wing angle of attack (without correction) } \\ C_{L, \text { eff }} & =\text { effective lift coefficient (including propulsive forces) } \\ C_{L, \text { unblown }} & =\text { unblown lift coefficient } \\ C_{L, \text { wing }} & =\text { wing lift coefficient (not including propulsive forces) } \\ D_{p} & =\text { propeller diameter } \\ \delta_{\alpha} & =\text { wing angle of attack deflection/correction } \\ \delta_{f} & =\text { flap deflection } \\ J & =\text { advance ratio } \\ R & =\text { propeller radius } \\ \theta_{p} & =\text { propeller inclination } \\ x_{p} & =\text { propeller offset } \\ z_{p} & =\text { propeller height (corrected) } \\ z_{p} * & =\text { propeller height for maximum lift (corrected) } \\ z_{p, \text { input }} & =\text { input propeller height (without correction) }\end{array}$

\section{Introduction}

Distributed electric propulsion (DEP) technologies employ multiple electrically powered propulsors, installed in such a way as to produce beneficial synergistic propulsion-airframe integration effects. In typical DEP aircraft concepts, propulsors are smaller in scale, greater in number, and/or are installed in more unconventional locations than their conventional combustion engine-powered counterparts. Both NASA and the private sector have already proposed several aircraft concepts which employ various forms of DEP. For example, concepts such as NASA's Puffin [1], e-ATLIT [2], LEAPTech [3], GL-10 [4], and X-57 Maxwell [5], as well as the Joby S2 [6], Lilium Jet [7], Aurora eVTOL [8], and

\footnotetext{
* Pathways Intern, Aeronautics Systems Analysis Branch, 1 N. Dryden St. MS 442, AIAA Student Member.

${ }^{\dagger}$ Associate Professor, School of Aerospace Engineering, 270 Ferst Drive, AIAA Associate Fellow.

$\lessgtr$ Aerospace Engineer, Aeronautics Systems Analysis Branch, 1 N. Dryden St. MS 442, AIAA Member.
} 
Airbus $\mathrm{A}^{3}$ Vahana [9] all leverage DEP to perform missions that would be either economically unviable or technically infeasible with conventional combustion engines. The focus of this paper is on one particular DEP technology currently being demonstrated on the NASA X-57 Maxwell—the high-lift propeller system (HLPS) [10]—shown in Figure 1$]$

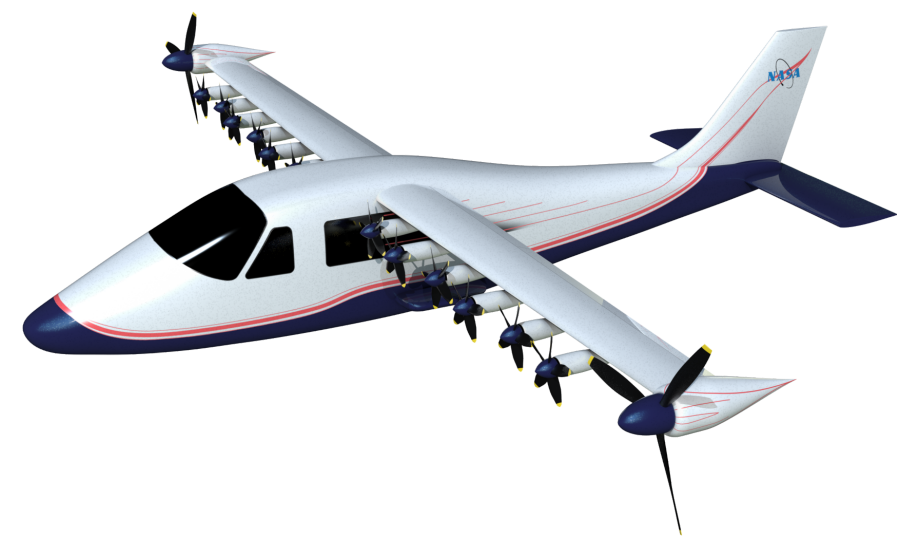

Fig. 1 The NASA X-57 Maxwell is a technology demonstrator for two DEP technologies, the high-lift propeller system and wingtip propellers.

It is well understood that the design of conventional aircraft—especially those of smaller scale—compromises on wing area in order to satisfy low speed performance requirements. The resulting wings are larger than optimal for efficient high-speed cruise, despite the addition of passive high-lift devices such as flaps and slats. The purpose of a HLPS is to reduce the need to compromise by providing an alternative source of lift augmentation via wing blowing. Consisting of an array of propellers installed upstream of the wing leading edge, a HLPS accelerates the flow observed by the wing, thereby increasing the wing's effective lift coefficient. In the case of the X-57, lift coefficients of 4.5 or greater are possible during takeoff, approach, and landing with moderate blowing of a flapped wing [11-13]. The propeller blades (of the HLPS) then conformally fold away against their nacelles during cruise to reduce drag [14]. The result is a 58\% reduction in wing area when compared to the Tecnam P2006T F $^{\circ}$ and dramatically more efficient cruise performance.

In designing the X-57's HLPS, several constraints were applied to simplify the design [15]. In particular, the high-lift propellers' longitudinal degrees of freedom were constrained to be equal: all propellers had the same offset relative to the wing in the $x$ and $z$ direction $\$$ and all nacelles were inclined to be aligned with the freestream in cruise. However, it is reasonable to expect that the optimal HLPS design in terms of lift augmentation would involve different installation geometries for each high-lift propeller since local flow conditions vary across the wing's span. Unfortunately, a search of the literature provided very little data on the relationships between installation geometry and propeller-wing interaction. A study by Gentry et al. [16] had good resolution in propeller inclination but only two settings each of $x$ and $z$ offset. Another study by Veldhuis [17] provided a detailed study of the variables of interest but only at cruise conditions.

As a first step toward improving HLPS design, an experiment was conducted to better understand the effects of varying installation geometry on lift augmentation. Experiment variables included the degrees of freedom described above, as well as flap deflection and angle of attack to capture takeoff and landing flight conditions. While many measurements were taken during the experiment, the focus of this paper will be purely on lift and lift augmentation. Section II describes the wind tunnel model setup and experimental procedure, Section III presents a discussion of the relevant results, and Section IV presents a model of propeller height for maximum lift augmentation.

\section{Experiment Design and Setup}

\section{A. Experiment Variables}

Table 1 describes the geometric and operational variables included in this experiment and gives their range of settings. The core experiment consisted of a full factorial design-of-experiment with the variables and settings listed

\footnotetext{
*The X-57 is a Tecnam P2006T retrofitted with wingtip propellers, a HLPS, and a smaller wing

${ }^{\dagger}$ Technically, the $x$ offsets were staggered along the span, but the stagger was about a nominal $x$ offset and was for safety rather than performance.
} 
in Table 1 Figure 2 illustrates the variables defining installation geometry and defines their positive directions. In regard to the propeller position variables, the propeller's origin is defined as the intersection of the propeller's axis of rotation and the propeller hub's back plane. The settings of $\delta_{f}$ and $\alpha_{w}$ were selected such that both cruise and takeoff and landing conditions could be captured. Settings of $z_{p}$ and $\theta_{p}$ were selected to give a good resolution, but $x_{p}$ was limited to two settings due to the effort required to adjust it. The 10 " propeller was selected for a diameter-to-chord ratio close to that of the X-57's high-lift propellers, while the 18" propeller served to give insight into the effect of increasing diameter-to-chord ratio. The two settings of $J$ selected represented high and low thrust settings that still maintained reasonably high propeller efficiency based on the APC propellers' performance data [18, 19].

Table 1 Experiment variables, variable settings, and variable descriptions.

\begin{tabular}{|c|c|c|}
\hline Symbol & Values & Variable Name and Description \\
\hline$\delta_{f}$ & $0,10,30$ degrees & $\begin{array}{l}\text { Flap deflection. Angle between original chord line and } \\
\text { portion of chord line deflecting with flap. }\end{array}$ \\
\hline$\alpha_{w}$ & $0,3,6,9,12,15,18$ degrees & $\begin{array}{l}\text { Wing angle of attack. Angle between chord line and } \\
\text { freestream velocity vector. }\end{array}$ \\
\hline$z_{p}$ & $\begin{array}{l}-5,-4,-3,-2.5,-2,-1.5,-1,-2 / 3,-1 / 3,0,1 / 3 \\
2 / 3,1,1.5,2,2.5,3,4,5 \text { inches }\end{array}$ & $\begin{array}{l}\text { Propeller height. Normal distance from chord line to } \\
\text { propeller origin. }\end{array}$ \\
\hline$x_{p}$ & 9,11 inches & $\begin{array}{l}\text { Propeller offset. Chord-wise component of distance from } \\
\text { wing leading edge to propeller origin. }\end{array}$ \\
\hline$\theta_{p}$ & $-8,-4,-2,0,2,4,8$ degrees & $\begin{array}{l}\text { Propeller inclination. Angle between propeller axis and } \\
\text { chord line. }\end{array}$ \\
\hline$D_{p}$ & 10,18 inches & Propeller diameter. APC Thin Electric $10 \times 7$ and $18 \times 12$. \\
\hline$J$ & $0.4,0.7$ & $\begin{array}{l}\text { Advance ratio. Varied by keeping freestream velocity } \\
\text { constant }(15 \mathrm{~m} / \mathrm{s}) \text { and changing motor speed. }\end{array}$ \\
\hline
\end{tabular}

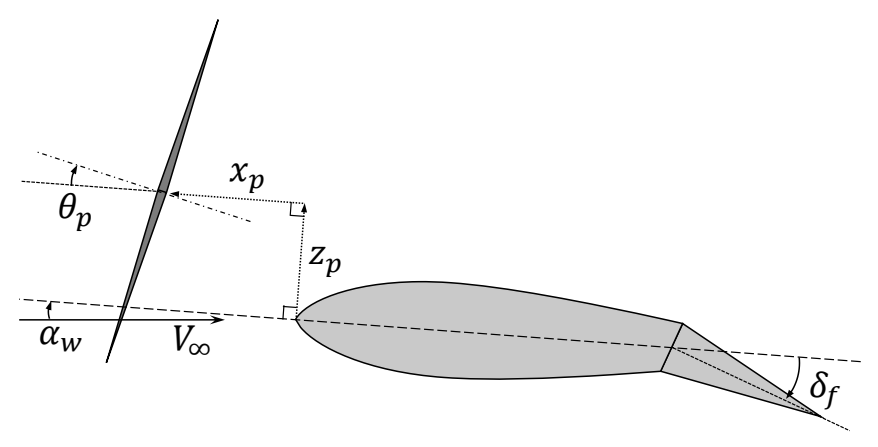

Fig. 2 Definition of experimental variables with arrowheads denoting positive direction. The two remaining experiment variables not labeled are advance ratio and propeller diameter.

\section{B. Wind Tunnel Model Description}

The wind tunnel model, shown in Figure 3 , consists of a rectangular wing with a single motor/propeller mounted at the mid-span. The wing has a 41.58" span and 10" chord with a symmetric NACA 0016 airfoil cross section and a $30 \%$ plain flap hinged at the lower surface. The wing was mounted vertically in the 42 " $\times 42$ " closed test section of the Georgia Institute of Technology Low Speed AeroControls Tunnel, depicted in Figure 4, at the centerline, almost spanning the entire height of the test section. A $1 / 8$ " gap was present between the wing ends and tunnel ceiling and floor plate. This floor plate is a $1 / 16$ " thick piece of acrylic used to cover the access hatch through which the model was inserted. The wing is constructed from three equal span sections with each section consisting of three pieces-upper surface, lower surface, and flap-manufactured from $\mathrm{CNC}$ milled high density polyethylene. A 1" $\times 1$ " extruded T-slot 
aluminum beam serves as a spar (positioned at the $1 / 4$ chord) about which the upper and lower surface pieces are secured with aluminum binding posts. The flap is attached to the lower surface by aluminum piano hinges, and each flap piece is controlled by a Hitec HS-7954SH servo motor embedded inside the corresponding wing section. An aluminum collar underneath the bottom wing section prevents the wing from slipping down the spar. The wing spar is supported on each end by tapered bearings housed in aluminum blocks mounted to two ATI Gamma six-axis load cells.

The single Neumotor $32101.5 \mathrm{Y} 220 \mathrm{Kv}$ motor powering the propeller is mounted to a third ATI Gamma load cell, forming the propulsion subassembly. The propulsion subassembly can then be mounted to the wing in one of two ways. In the variable geometry configuration, the propulsion subassembly is mounted to the carriage of a custom built linear actuator that traverses in the $z_{p}$ direction, hereafter referred to as the 'height arm.' A pin-locked hinge is integrated into the linear actuator's carriage, which allows propeller inclination to vary. In the clean fixed configuration, a rigid aluminum beam connects the propulsion subassembly to the spar, and a 3D printed ABS plastic fairing covers the exposed beam and cables for a cleaner transition into the wing. The purpose of the clean fixed configuration was to give an idea of how much interference is added by the presence of the height arm and lack of fairing in the variable height configuration. This configuration was also used to measure the unblown (i.e. propeller off) performance.
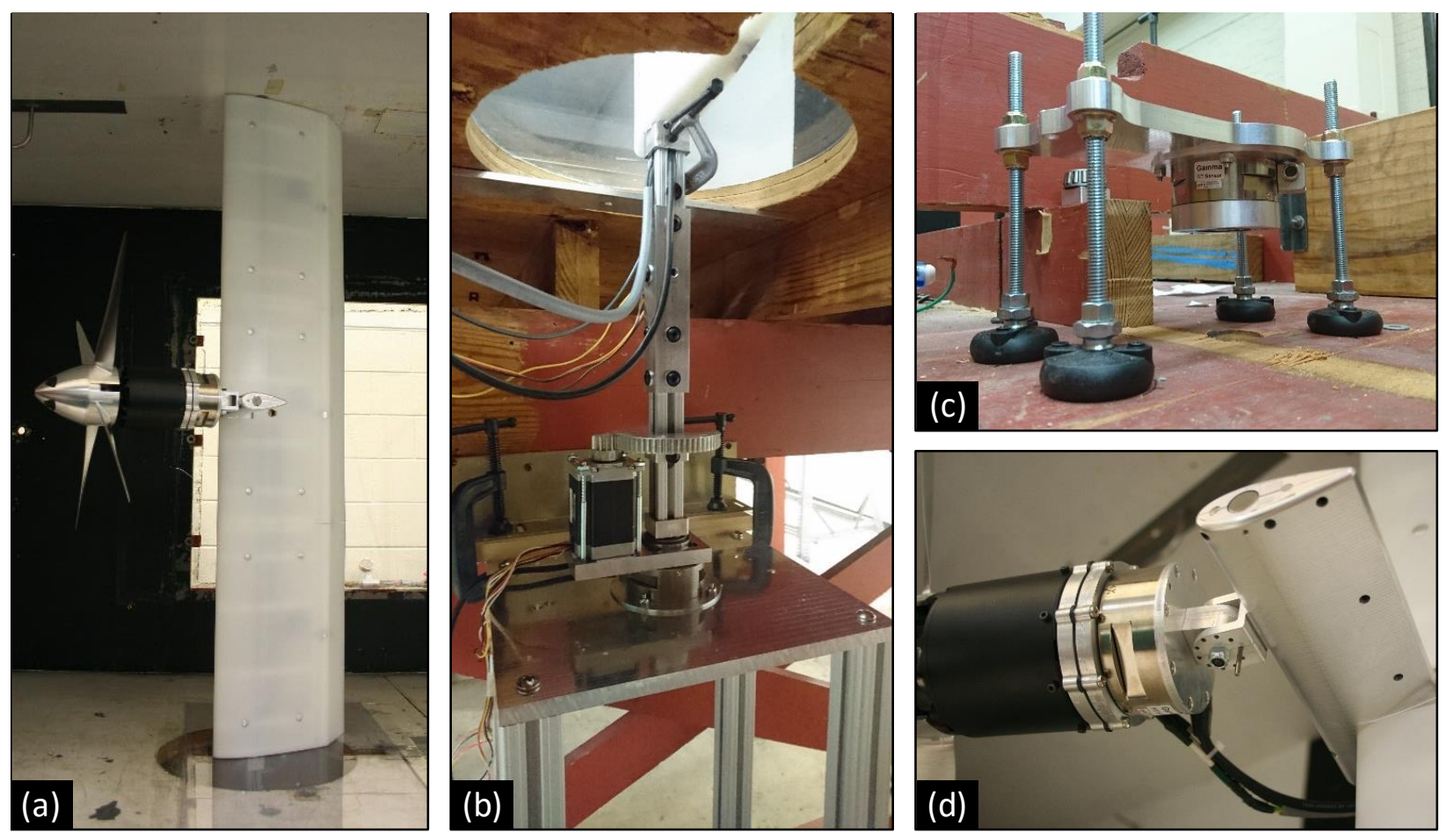

Fig. 3 Wind tunnel model components: (a) Wing in variable propeller height configuration at maximum angle of attack, flap deflection, and propeller height (propeller shown was used for testing purposes only and was not used in the experiment). (b) Angle of attack control mechanism mounted on bottom load cell. (c) Top load cell stand prior to installation of wing spar. (d) Propulsion subassembly mounted to height arm with propeller inclination set to $10^{\circ}$ and propeller height set to $3 "$.

\section{Wind Tunnel Model Control}

Control of the wind tunnel model is divided between manual and automated variables. $x_{p}, \theta_{p}$, and $D_{p}$ are adjusted manually, requiring the tunnel and motor to be turned off. By default, the height arm sets $x_{p}$ to $9^{\prime \prime}$ when $\theta_{p}=0^{\circ}$. A 2" long aluminum beam can be installed behind the height arm to extend $x_{p}$ to $11^{\prime \prime} . \theta_{p}$ is set by a locking pin on the hinge integrated into the height arm's carriage. By changing the position of this locking pin, $\theta_{p}$ can be varied in increments of $2^{\circ}$ between $-10^{\circ}$ and $10^{\circ}$. To change $D_{p}$, two propellers with similar efficiency vs. $J$ curves were used in this experiment: APC Thin Electric $10 \times 7$ and $18 \times 12$.

Control of $\alpha_{w}, z_{p}, \delta_{f}$, and $J$ are automated through LabView. To vary $\alpha_{w}$, an Applied Motion Products HT23-601 


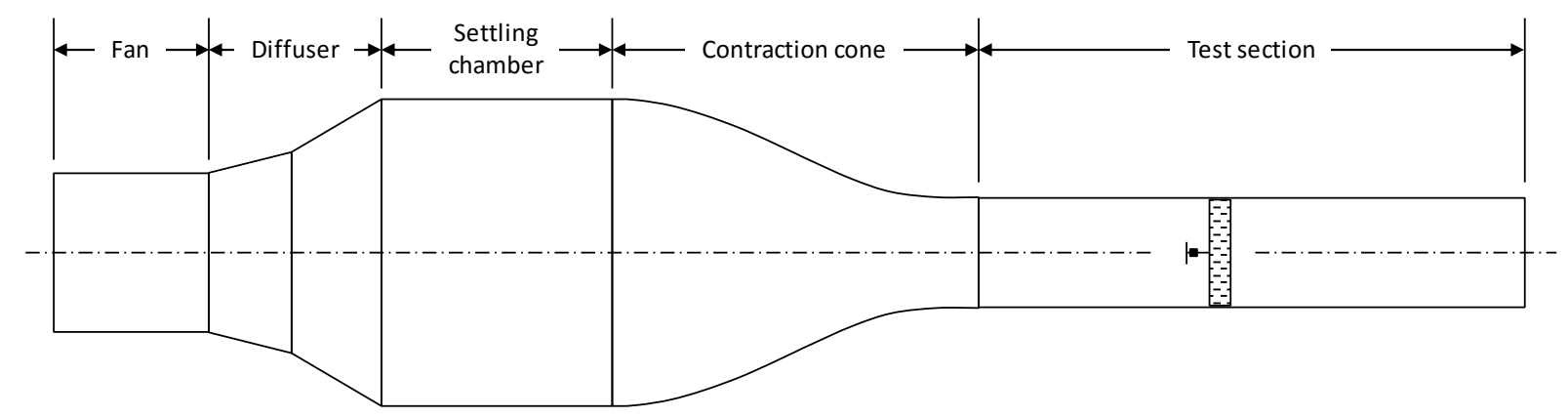

Fig. 4 Side view of Georgia Institute of Technology Low Speed AeroControls Tunnel with approximate location of wind tunnel model.

stepper motor underneath the tunnel floor rotates the spar at a 5:1 gear ratio. The stepper motor is driven by a SMD-7613 stepper drive, which receives commands from LabView. To vary $z_{p}$, another SMD-7613 drives an Applied Motion Products HT11-020 stepper motor on the height arm linear actuator. While the height arm only allows for 5" of traverse starting at $z_{p}=0$, its installation can be manually inverted to traverse the opposite side of the wing. To control $\delta_{f}$ and $J$ (via motor speed), an NI-9401 CompactDAQ module is configured to output pulse width modulation signals to the flap servo motors and a Phoenix Edge HV 60 electronic speed controller, respectively. In the case of motor speed, a PID controller is employed to prevent motor speed from drifting away from target settings.

In the clean fixed configuration, control methods are identical except that $x_{p}$ and $\theta_{p}$, and $z_{p}$ are fixed to $9^{\prime \prime}, 0^{\circ}$, and 0 ", respectively.

\section{Measurements and Data Acquisition}

In all, 23 distinct measurements were made at each data point. These include three forces and three moments from each of the three six axis load cells, freestream dynamic pressure from an ACI A/DP2-11-10 differential pressure transducer connected to a pitot-static tube installed upstream of the model, motor speed from the electronic speed controllen and air temperature, pressure, and relative humidity from an Extech SD700 environmental data logger. Load cell, dynamic pressure, and motor speed signals were read at $2 \mathrm{kHz}$ and averaged over four seconds using a National Instruments CompactDAQ system fitted with NI-9239 modules. The sample rate was determined by the Nyquist frequency of the motor speed signal, which pulses once for each of the motor's six pole pairs per revolution. With a theoretical maximum motor speed of 10,000 rpm, the maximum frequency of the motor speed signal is $1 \mathrm{kHz}$. Prior to each sampling period, a two second delay was added to allow for the flow to reach steady state.

\section{E. Corrections}

Corrections were required for two input variables, $\alpha_{w}$ and $z_{p} . \alpha_{w}$ was found to deviate from the desired input angle of attack, $\alpha_{w \text {,input }}$, due to non-zero $z_{p}$ settings generating large pitching moments and causing the spar to twist. To correct for this, the angular deflection at each wing tip was measured at static conditions with the 18" propeller running at various speeds and $z_{p}$ settings. A linear relationship was found between the average of the deflections, $\delta_{\alpha}$, and the measured pitching moment, which is consistent with theory for a simple beam under torsional load. The deflection measurements and fitted calibration curve are shown in Figure 5

A correction was required for $z_{p}$ because the hinge for varying $\theta_{p}$ is offset from the propeller origin. In addition to the distance traversed on the height arm, $z_{p, \text { input }}$, the propeller origin is further displaced in the $z_{p}$ direction when $\theta_{p}$ is non-zero. Although non-zero $\theta_{p}$ also has a small effect on $x_{p}$, the error was deemed insignificant compared to the difference between $x_{p}$ settings. The offset was measured to be 7.4" and is not affected by changes in $x_{p}$.

The data presented in Section III are in terms of corrected $\alpha_{w}$ and $z_{p}$, defined as

$$
\begin{aligned}
\alpha_{w} & =\alpha_{w, \text { input }}+\delta_{\alpha} \\
z_{p} & =z_{p, \text { input }}+7.4 \sin \left(\theta_{p}\right)
\end{aligned}
$$

\footnotetext{
†The electronic speed controller outputs a speed-dependent square wave signal which is separate from the throttle-setting pulse width modulation input signal mentioned earlier.
} 


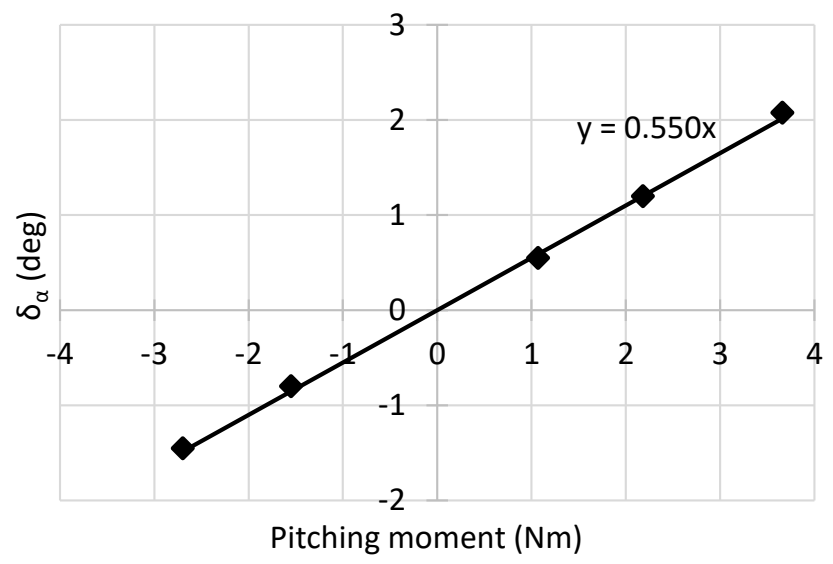

Fig. 5 Relationship between pitching moment and angle of attack deflection.

No other corrections were made to the data (e.g. solid blockage, wall effects) as the data is intended to be corrected with CFD simulation as part of a later effort.

\section{Results}

The evaluation of HLPS performance is somewhat unique in that, as a high-lift device, the desired result is maximum lift with almost no regard for drag. In fact, because a HLPS produces additional thrust, higher induced or parasite drag may be desired to prevent excessive approach speeds [20]. Of course, drag does enter the equation when the trade-off of having exposed nacelles during cruise is considered, but that is outside the scope of this study.

In this study, the primary metric of interest and focus of discussion is the effective lift coefficient, $C_{L, e f f}$, defined as the total nondimensional lift of the wing-propeller system inclusive of any forces generated by the propulsion subassembly in the lift direction. However, $C_{L \text {,wing }}$, the lift coefficient with propulsive forces subtracted out, is plotted for comparison. Lift augmentation, in the forms of $C_{L, \text { eff }}-C_{L, \text { unblown }}$ and $C_{L, \text { eff }} / C_{L, \text { unblown }}$, where $C_{L, \text { unblown }}$ is the lift coefficient of the unblown wing (in the clean fixed configuration), is plotted where appropriate.

The reader is reminded that the model only consists of one propeller so that only $24 \%$ or $43 \%$ of the wing is blown with the 10" or 18" propeller, respectively. The following $\Delta C_{L}$ values should be multiplied by the inverse of the blown fraction to provide a first order estimate of lift augmentation for a fully blown wing in the absence of finite wing effects.

Lastly, due to the corrections made to $\alpha_{w}$ and $z_{p}$, the resulting data no longer lie along constant values of either variable. To better illustrate the effect trends, the graphs in the Appendix were generated from linear interpolations of the experimental data in unstalled regions of $\alpha_{w}$. Markers shown in these graphs are purely for the purpose of differentiating between curves and do not represent data points.

\section{A. Effect of Propeller Height}

Figures A.1 A.3 show the effect of $z_{p}$ (normalized by propeller radius, $R$ ) on $C_{L, \text { wing }}$ and $C_{L, \text { eff }}$ for $\delta_{f}=$ $0^{\circ}, 10^{\circ}$, and $30^{\circ}$, respectively, when $x_{p}=9^{\prime \prime}, \theta_{p}=0^{\circ}, D_{p}=10^{\prime \prime}$, and $J=0.4$. These graphs demonstrate a general trend observed throughout the data: the $z_{p} / R$ for maximum $C_{L, e f f}$, hereby denoted as $z_{p}^{*} / R$, decreases with increasing $\alpha_{w}$ and $\delta_{f}$. Data from Veldhuis's [17] experiment, shown in Figure 6] supports this observation. A simple explanation for this trend could be that, since increasing both $\alpha_{w}$ and $\delta_{f}$ shifts the center of the wing's projected frontal area lower, decreasing $z_{p} / R$ allows more of the slipstream cross-sectional area to impinge upon the wing. However, the authors

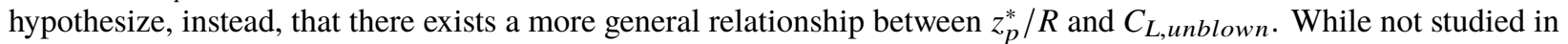
this experiment, we believe that the same trend would be observed were $C_{L, \text { unblown }}$ to be increased by other factors which do not lower the center of the wing's projected frontal area, such as airfoil camber or thickness.

Another observation made from Figures A.1 A.3 is that larger $\alpha_{w}$ and $\delta_{f}$ configurations tend to result in larger amounts of lift augmentation in terms of $\Delta C_{L}$ when other variables are held constant. Though perhaps trivially intuitive,

\footnotetext{
$\S$ The $z_{p}$ used here is defined by Veldhuis as the component of the distance from the propeller origin to the wing quarter chord normal to the freestream direction, as illustrated in Figure 5.27 of Ref. [17]. Fortunately, the discrepancy is small for small angles of attack and is overlooked here.
} 


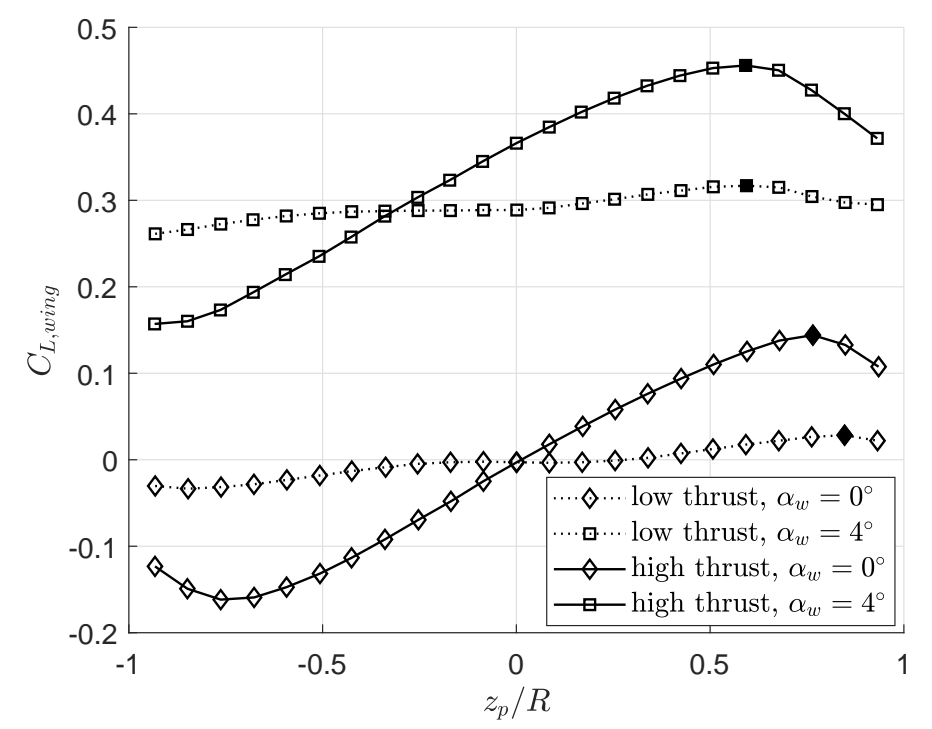

Fig. 6 Effect of propeller heigh [ 8 on wing lift coefficient as adapted from Figure 5.29 of Veldhuis [17]. The shaded points denote the point of maximum lift for each configuration.

this trend is reassuring to see as it implies that an airplane entering increasingly extreme high-lift conditions will see increasingly higher (absolute) lift augmentation. The same trend is not observed when lift augmentation is viewed as a fraction of $C_{L, \text { unblown }}$. From this perspective, the maximum $C_{L, \text { eff }}$ attainable over the explored range of $z_{p}$ is found to be consistently $20 \%$ to $30 \%$ over $C_{L \text {,unblown }}$. The exceptions are when the unblown wing is operating at very low $C_{L}$ or is beginning to stall, in which case the percentage increase is significantly higher. For reference, the lift curves of the unblown wing at each flap deflection setting is plotted in Figure 7 .

Lastly, it is important to note that improper application of a HLPS can sometimes be detrimental to lift. As seen in Figures A.1 and A.2, low settings of $z_{p} / R$ actually resulted in values of $C_{L, \text { eff }}$ lower than $C_{L, \text { unblown }}$ when both $\alpha_{w}$ and $\delta_{f}$ are low (i.e., at cruise conditions).

\section{B. Effect of Propeller Inclination}

Figures A.4 A.6 show curves of $C_{L, w i n g}$ and $C_{L, \text { eff }}$ vs. $z_{p} / R$ over a range of $\theta_{p}$ for $\delta_{f}=0^{\circ}, 10^{\circ}$, and $30^{\circ}$, respectively, when $x_{p}=9^{\prime \prime}, D_{p}=10^{\prime \prime}$, and $J=0.4$. Interestingly, the effect of $\theta_{p}$ is found to reverse depending on whether or not the lift component of propeller thrust is included. The trend of $C_{L \text {,wing }}$ increasing with decreasing $\theta_{p}$ is consistent with data from Veldhuis [17], shown in Figure 8, but the trend of $C_{L, e f f}$ increasing with increasing $\theta_{p}$ is the reverse of the trend found by Gentry et al. [16], demonstrated in Figure 9

A possible explanation for this contradiction is that the effect of $\theta_{p}$ is dependent on the relative performance of the propeller and wing, since non-zero $\theta_{p}$ induces two separate effects which counteract each other. When $\theta_{p}$ is positive, a component of the propeller's thrust is vectored into the lift direction, contributing to effective lift. Meanwhile, the downward inclination of the propeller slipstream lowers the effective angle of attack observed by the wing, reducing wing lift. The opposite is true when $\theta_{p}$ is negative; vectored propeller thrust detracts from effective lift while an increased effective angle of attack increases wing lift. In the case that a propeller is paired with a small wing with a shallow lift curve slope, $C_{L, e f f}$ is likely to trend positively with $\theta_{p}$ as the propeller's vectored thrust component overcomes the change in wing lift. In contrast, the same propeller paired with a large wing with a steep lift curve slope is likely to have $C_{L, \text { eff }}$ trend negatively with $\theta_{p}$ as the change in wing lift outweighs the vectored thrust. Examination of the wind tunnel model described in Gentry et al. reveals a propeller diameter-to-wing chord ratio of about 0.5 after flap deployment, which is half of the smallest ratio used in our experiment. Additionally, the wing of Gentry et al. was equipped with a $60^{\circ}$ Fowler flap and had a high maximum $C_{L, \text { unblown }}$, as is evidenced by Figure 9 . In contrast, the wing we used had a symmetric NACA 0016 airfoil with a $30^{\circ}$ plain flap.

Other observations of interest from Figures A.4 A.6 are that: 1) $z_{p}^{*} / R$ tends to increase with increasing $\theta_{p}, 2$ ) $C_{L, \text { wing }}$ becomes insensitive to $\theta_{p}$ at $z_{p} / R>z_{p}^{*} / R$, and 3) $C_{L, \text { eff }}$ becomes insensitive to $\theta_{p}$ at $z_{p} / R<z_{p}^{*} / R$. The 


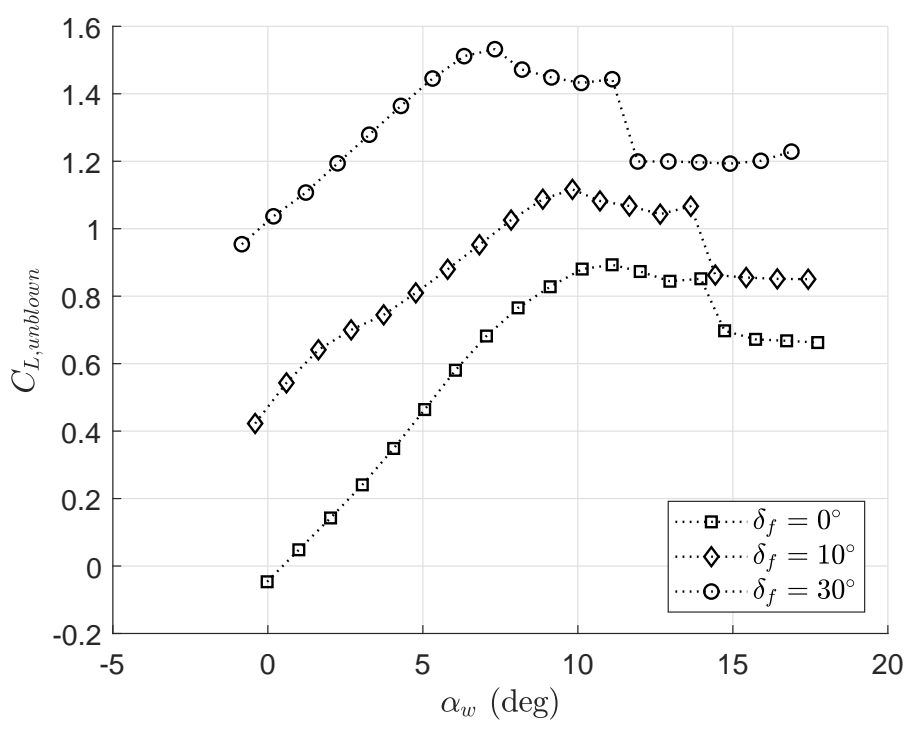

Fig. 7 Lift curves of the unblown wing.

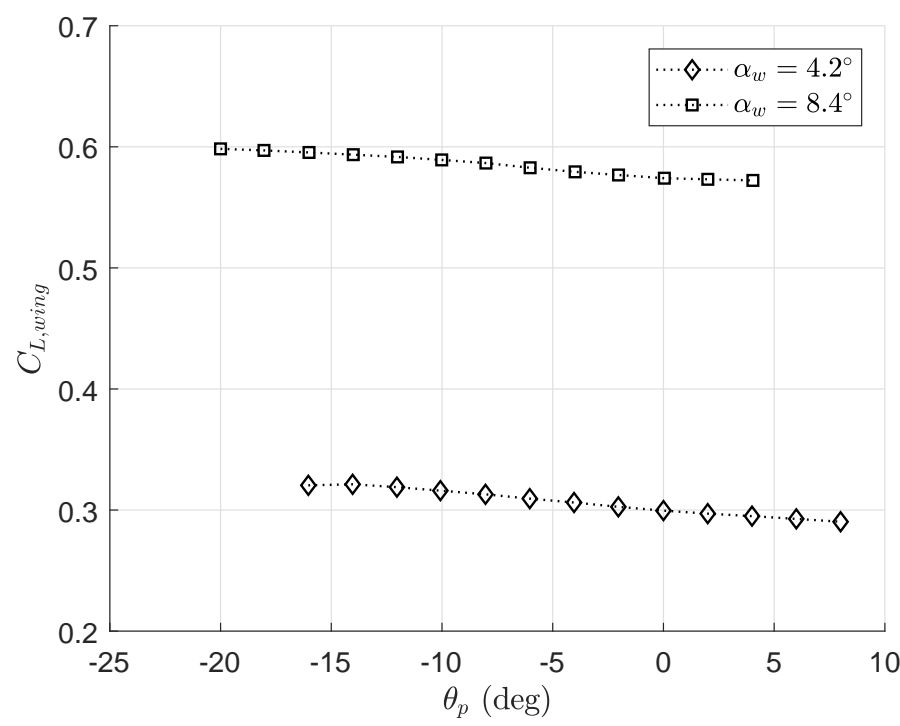

Fig. 8 Effect of propeller inclination on wing lift coefficient as adapted from Figure 5.37 of Veldhuis [17]. $z_{p} / R=0$.

second observation of $C_{L, \text { wing }}$ becoming insensitive at $z_{p} / R>z_{p}^{*} / R$ is most clearly observed in Figure A.6 where $z_{p}^{*} / R$ is lowest due to high $\delta_{f}$. Furthermore, this effect is retained in the $D_{p}=18$ " data shown in Figures A.7 A.9. The last observation of $C_{L, e f f}$ becoming insensitive to $\theta_{p}$ at $z_{p} / R<z_{p}^{*} / R$ is not retained in the $D_{p}=18$ " data, suggesting that this phenomenon is particular to the specific configuration settings. However, this may be a useful design point since the insensitivity would allow applicable high-lift propeller nacelles to be freely inclined for minimum drag penalty during cruise without affecting lift augmentation performance. A satisfactory explanation for either instance of insensitivity will require further studies. 


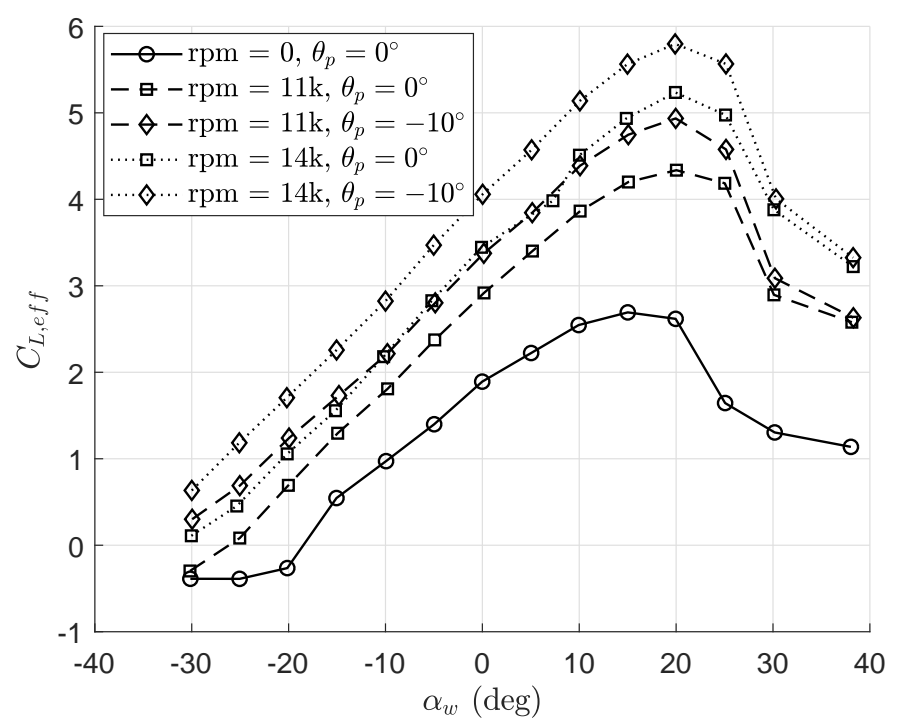

Fig. 9 Effect of propeller inclination on effective lift curves as adapted from Figure 11 of Gentry et al. [16].

\section{Effect of Propeller Offset}

Figures A.10 and A.11 show the effect of extending $x_{p}$ from 9" to $11 "$ for $D_{p}=10 "$ and 18 ", respectively, when $\theta_{p}=0^{\circ}$ and $J=0.4$. The general effect seems to be a small translation of $z_{p}^{*} / R$ to the left, which is reasonable because an increase in $x_{p}$ causes the vertical spacing between the propeller origin and the wing to grow when $\alpha_{w}$ is non-zero. This observation suggests that $z_{p}$ as defined by Veldhuis [17] may be a better independent variable for capturing propeller height effects.

Comparing Figure A.11 to Figure A.10 the 18" propeller seems to benefit more from the increased offset, especially at low $z_{p} / R$. A likely explanation is that the slipstream of the larger propeller requires more distance to fully contract and accelerate, leading to a larger benefits from increasing $x_{p}$.

A potential way to leverage the trends observed here is to increase $x_{p}$ to shift $z_{p}^{*} / R$ lower for cases where the desired $z_{p}$ setting is considered too high for other reasons. For example, cruise efficiency factors not considered here may favor placing HLPS nacelles far enough below the wing to prevent the nacelles' integration from weakening the local leading edge suction peak.

\section{Optimal Propeller Height vs. Unblown Lift Coefficient}

The hypothesis posited earlier about $z_{p}^{*} / R$ being a function of $C_{L, \text { unblown }}$ led to an attempt to model this relationship. Figure 10 shows a seemingly linear relationship between $z_{p}^{*} / R$ and $C_{L, \text { unblown }}$ for all data sets where $D_{p}=10$ " and $J=0.4$. As discussed earlier, non-zero $\theta_{p}$ has the general effect of shifting $z_{p}^{*} / R$, but a significant amount of the variance about the trendline is also due to noise in the data. Some portions of the data exhibited bumps/dips (e.g., the $\theta_{p}=8^{\circ}$ curve in the $\alpha_{w}=8^{\circ}$ plot of Figure A.5) or exceptionally flat regions (e.g., the $\theta_{p}=-8^{\circ}$ curve in the $\alpha_{w}=4^{\circ}$ plot of Figure A.5, which likely distorted the true $z_{p}^{*} / R$ value. The noise was likely caused by the lack of a nacelle for the motor and height arm, unsteady cyclic loading of the propellers at high flow incidence angles, or a combination of both.

For comparison, Figure 11 shows data from the applicable $D_{p}=18$ " $J=0.4$ configurations plotted with its own trendline and with that of the $D_{p}=10$ " $J=0.4$ configurations'. Here, "applicable" refers to the configurations which were able to bound $z_{p}^{*} / R$ within the explored $z_{p}$ range. Despite the fewer number of points from the $D_{p}=18$ " data, there is reasonable agreement except for a deviation by the last two (rightmost) sets of $\delta_{f}=30^{\circ}$ configurations, which correspond to $\alpha_{w}=6^{\circ}$ and $8^{\circ}$. These configurations were likely plagued by flow separation and/or unsteady loading, as is evidenced by the jaggedness of the data in the $\alpha_{w}=8^{\circ}$ graphs of Figure A.9. These two sets of points were excluded when generating the trendline.

The trendline equations are purposefully omitted since we can not yet confirm their generalizability to other 
configurations. The slope, intercept, and linearity may very well change with diameter-to-chord ratio, thrust-to-lift ratio, airfoil and flap type, etc. Instead, the goal is to alert designers to the presence of a potentially reliable relationship between these two variables.

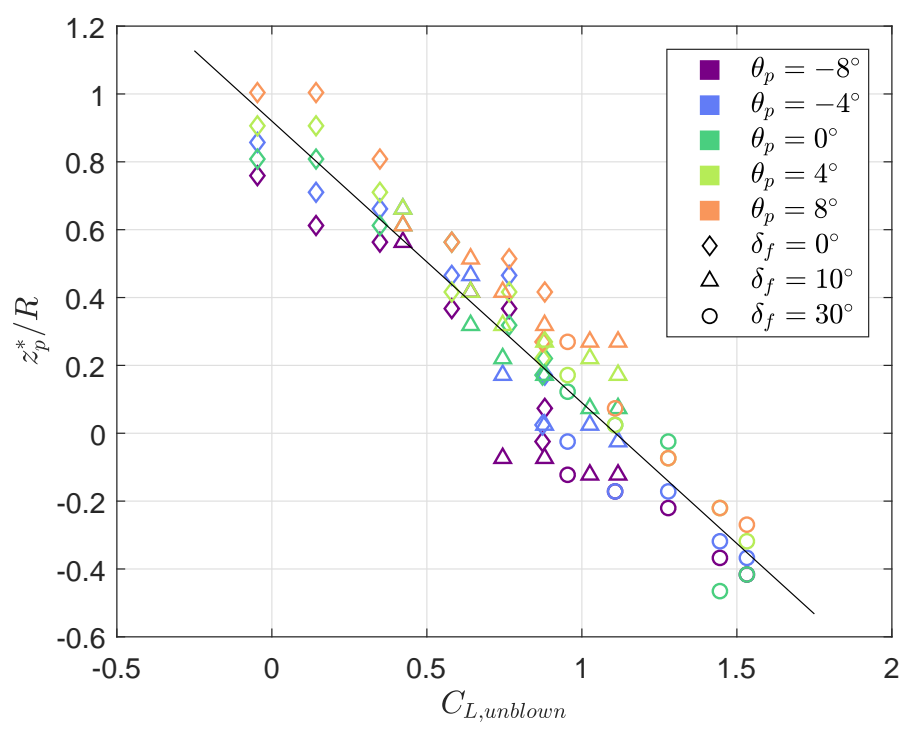

Fig. 10 Relationship between propeller height for maximum lift and unblown wing lift coefficient. $D_{p}=10^{\prime \prime}$ and $J=0.4$.

\section{Conclusion}

The purpose of the presented work was to experimentally explore the effects of HLPS installation geometry on lift augmentation performance. The results produced have enabled a number of observations:

1) The propeller height at which maximum lift coefficient is achieved decreases with increasing wing angle of attack and flap deflection.

2) The amount of lift augmentation achievable for a given thrust setting is a relatively consistent fraction of the unblown lift coefficient if the unblown lift coefficient is not close to zero or stalled.

3) Improper implementation of a HLPS can lead to a decrease in lift, even if thrust is not vectored downward.

4) Effective lift coefficient can trend positively or negatively with propeller inclination.

5) In certain configurations, the blown lift coefficient is insensitive to propeller inclination.

6) The propeller height at which maximum lift coefficient is achieved tends to increase with increasing propeller inclination.

7) Propeller offset has a relatively small effect on peak lift augmentation performance in the range of values tested.

In addition, based on the observations made, we have posited a hypothesis that there exists a (possibly linear) relationship between the normalized propeller height at which maximum lift coefficient is achieved and the unblown lift coefficient of the wing. A deeper investigation of this relationship would serve as an interesting topic for future work. 


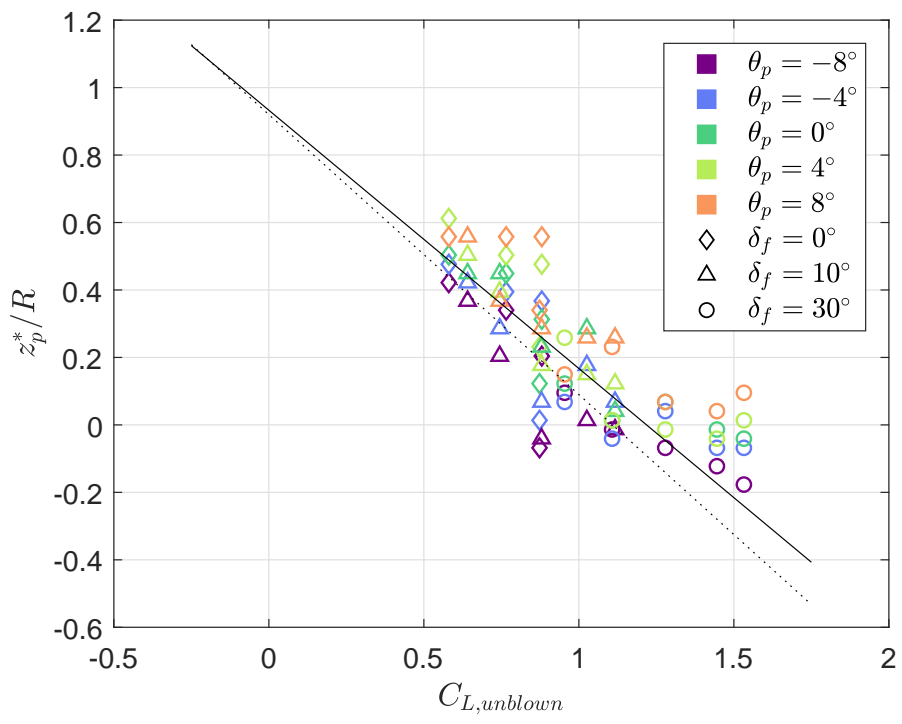

Fig. 11 Relationship between propeller height for maximum lift and unblown wing lift coefficient. $D_{p}=18^{\prime \prime}$ and $J=0.4$. The solid trendline shown is fitted to the plotted data while the dotted trendline is from Figure 10 , 


\section{A. Appendix}

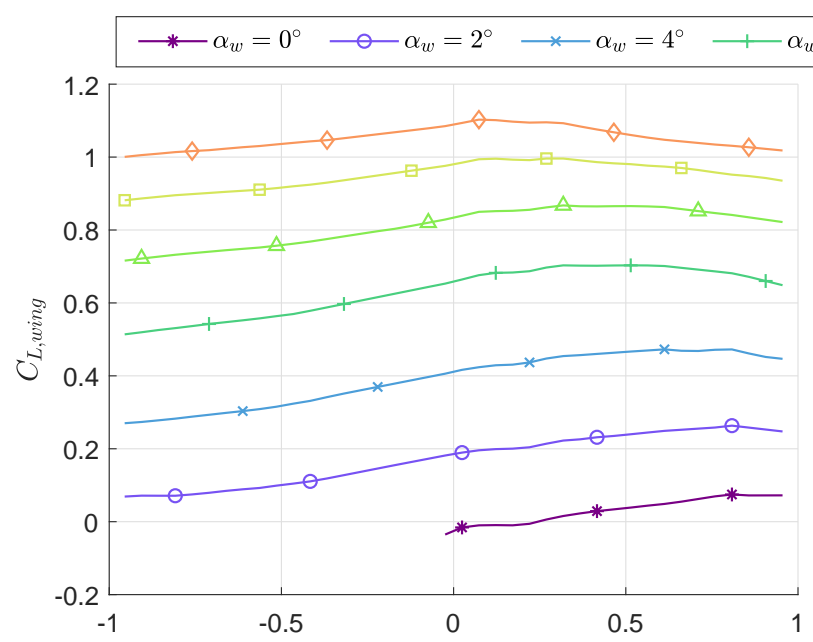

$$
\alpha_{w}=6^{\circ} \longleftarrow \alpha_{w}=8^{\circ} \longleftarrow \alpha_{w}=10^{\circ} \leadsto \alpha_{w}=12^{\circ}
$$
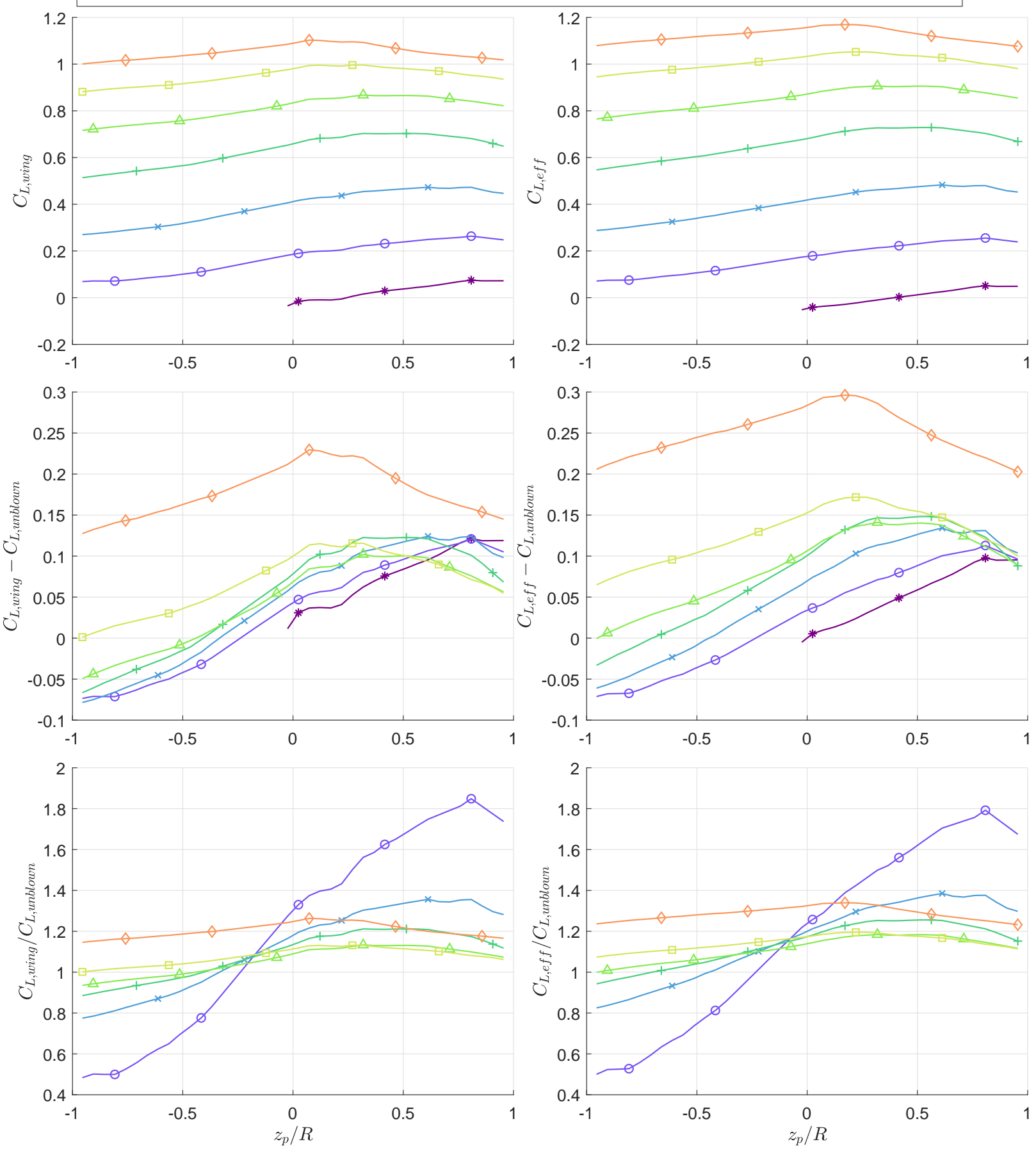

Fig. A.1 Effect of propeller height on lift coefficient and lift augmentation. $\delta_{f}=0^{\circ}, x_{p}=9^{\prime \prime}, \theta_{p}=0^{\circ}, D_{p}=10^{\prime \prime}$, and $J=0.4$. The $\alpha_{w}=0^{\circ}$ curves were removed from the last row of graphs due to near-zero values of $C_{L \text {,unblown }}$ resulting in very large (or negative) ratios. 

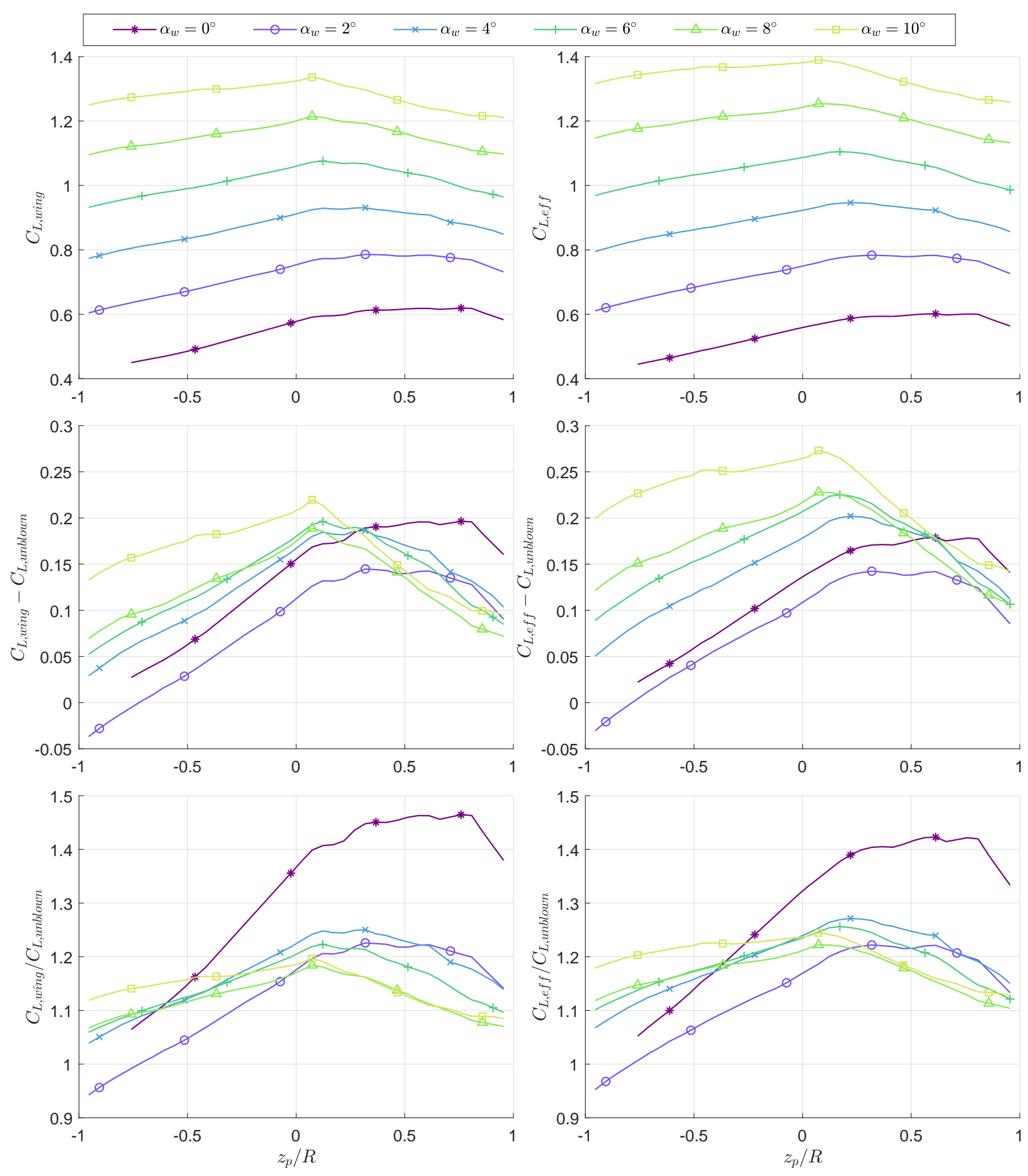

Fig. A.2 Effect of propeller height on lift coefficient and lift augmentation. $\delta_{f}=10^{\circ}, x_{p}=9^{\prime \prime}, \theta_{p}=0^{\circ}$, $D_{p}=10^{\prime \prime}$, and $J=0.4$. 

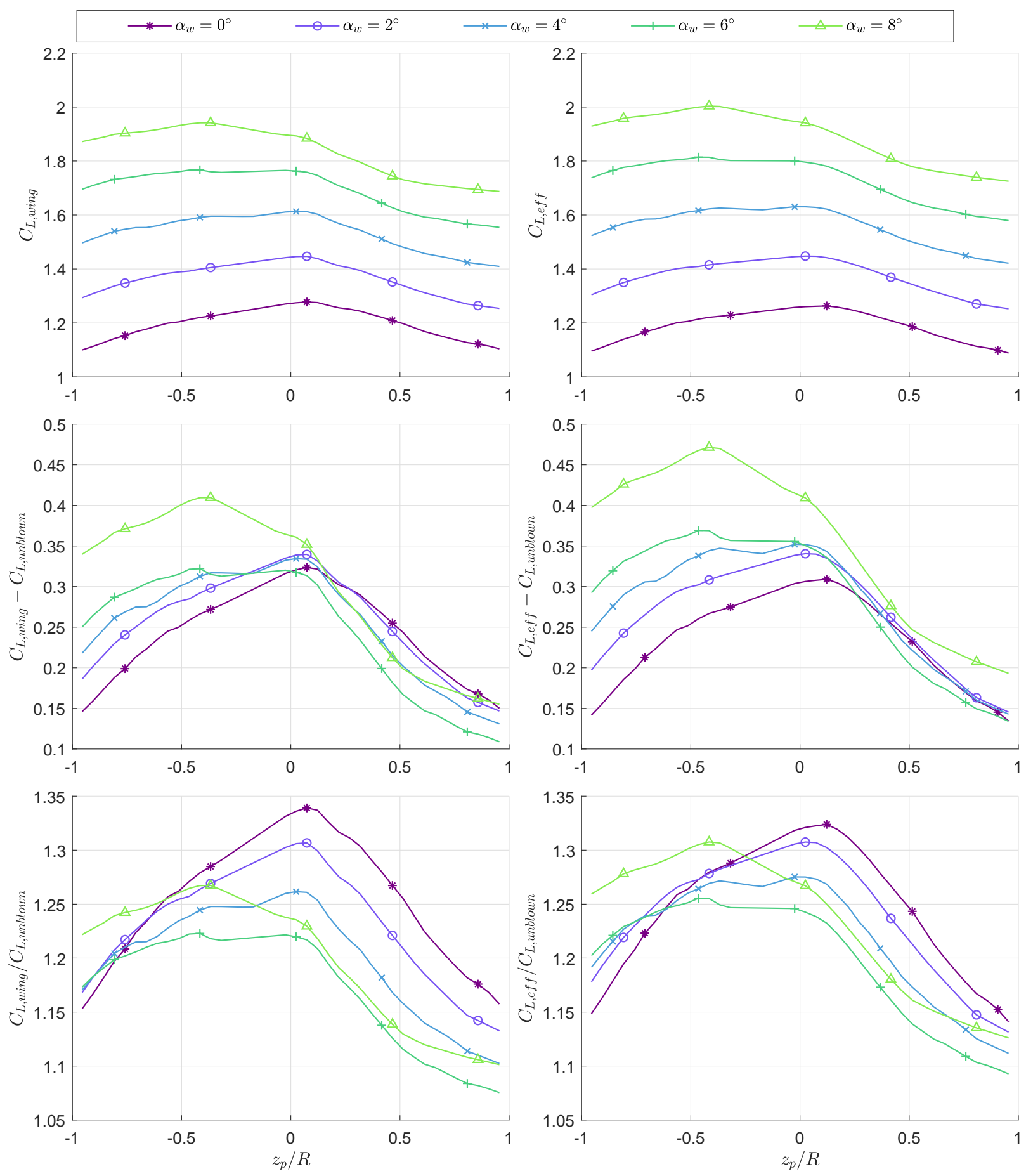

Fig. A.3 Effect of propeller height on lift coefficient and lift augmentation. $\delta_{f}=30^{\circ}, x_{p}=9^{\prime \prime}, \theta_{p}=0^{\circ}$, $D_{p}=10^{\prime \prime}$, and $J=0.4$. 

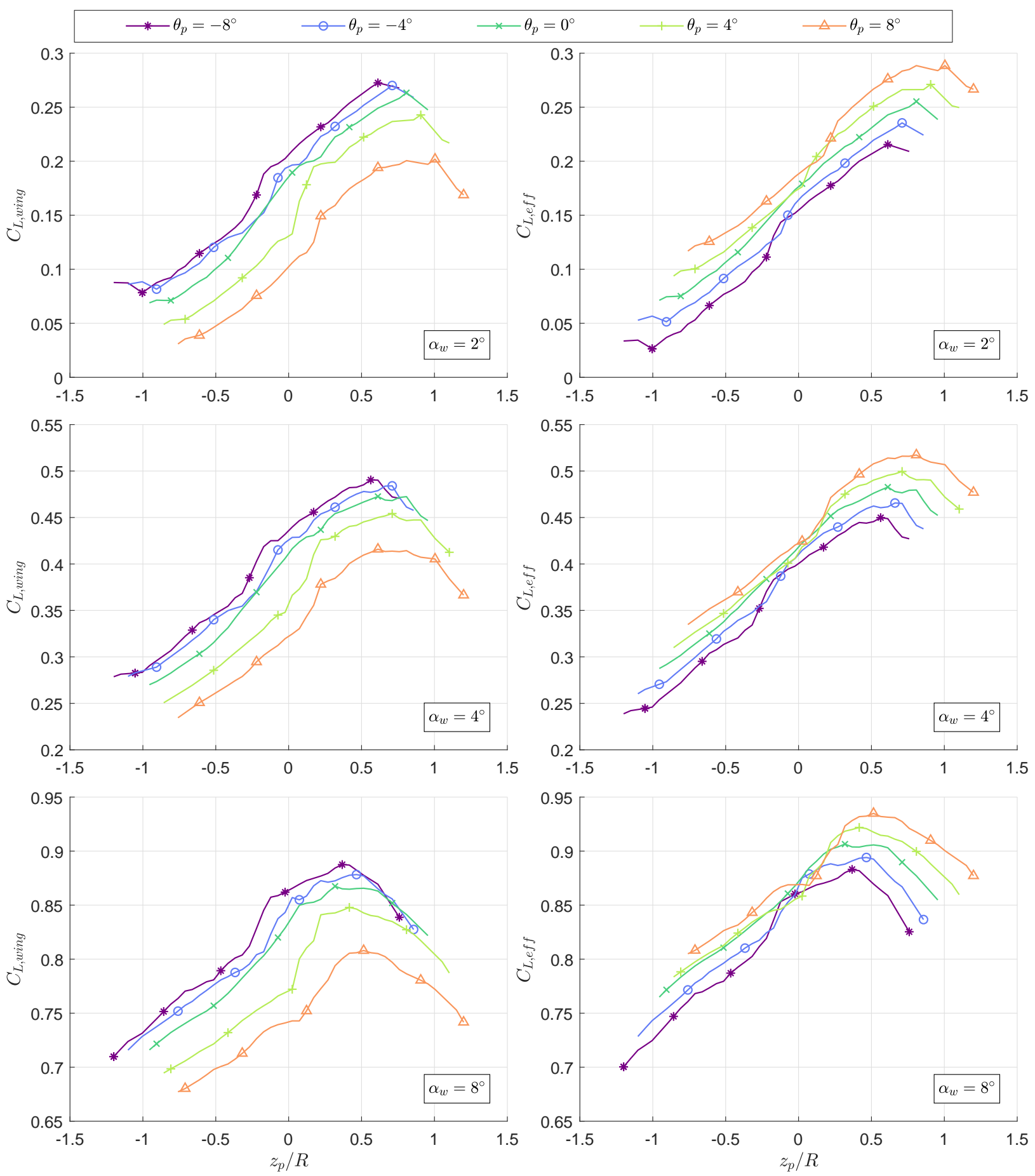

Fig. A.4 Lift coefficient vs. propeller height over a range of propeller inclinations at three angles of attack. $\delta_{f}=0^{\circ}, x_{p}=9^{\prime \prime}, D_{p}=10^{\prime \prime}$, and $J=0.4$. 

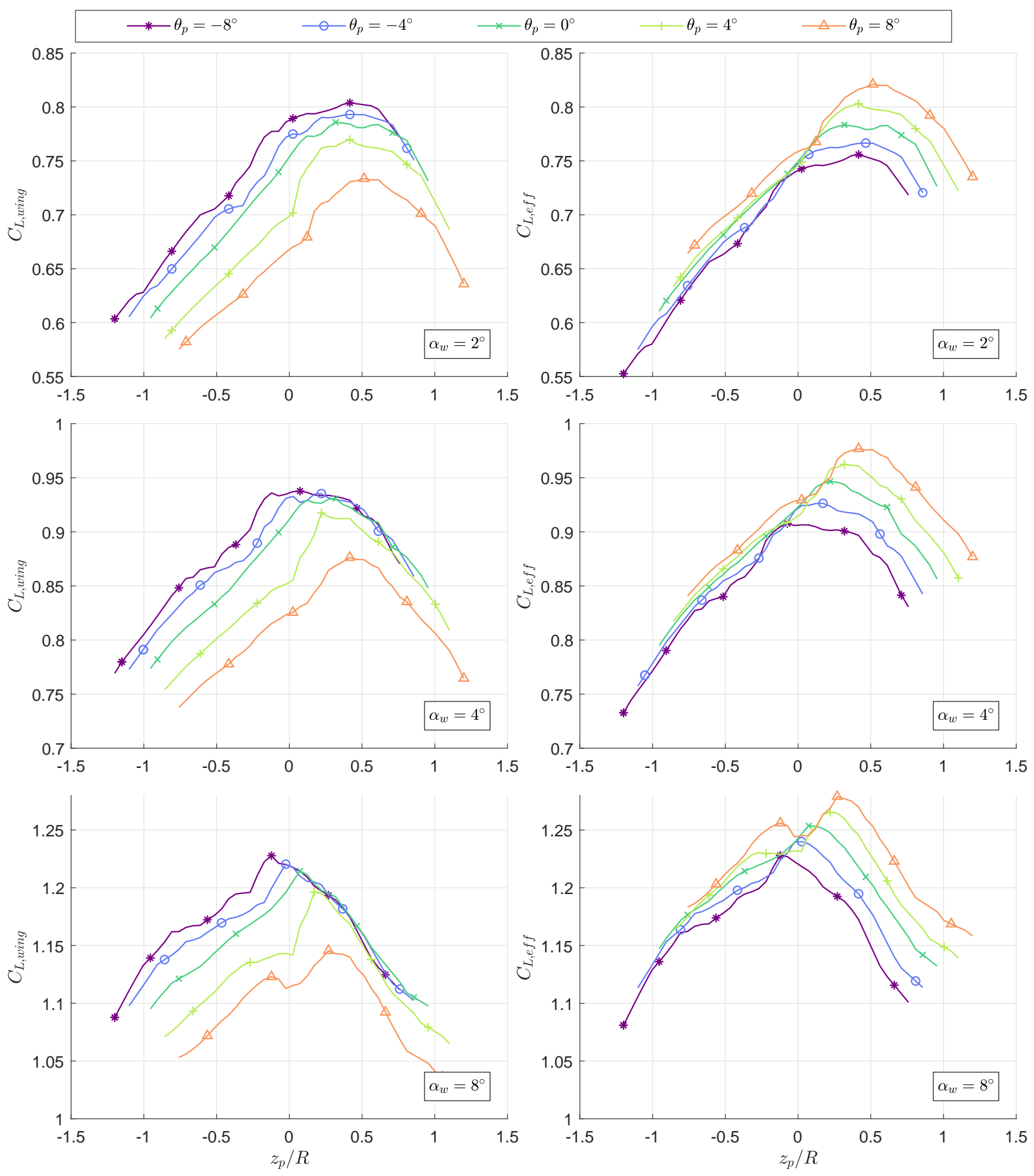

Fig. A.5 Lift coefficient vs. propeller height over a range of propeller inclinations at three angles of attack. $\delta_{f}=10^{\circ}, x_{p}=9^{\prime \prime}, D_{p}=10^{\prime \prime}$, and $J=0.4$. 

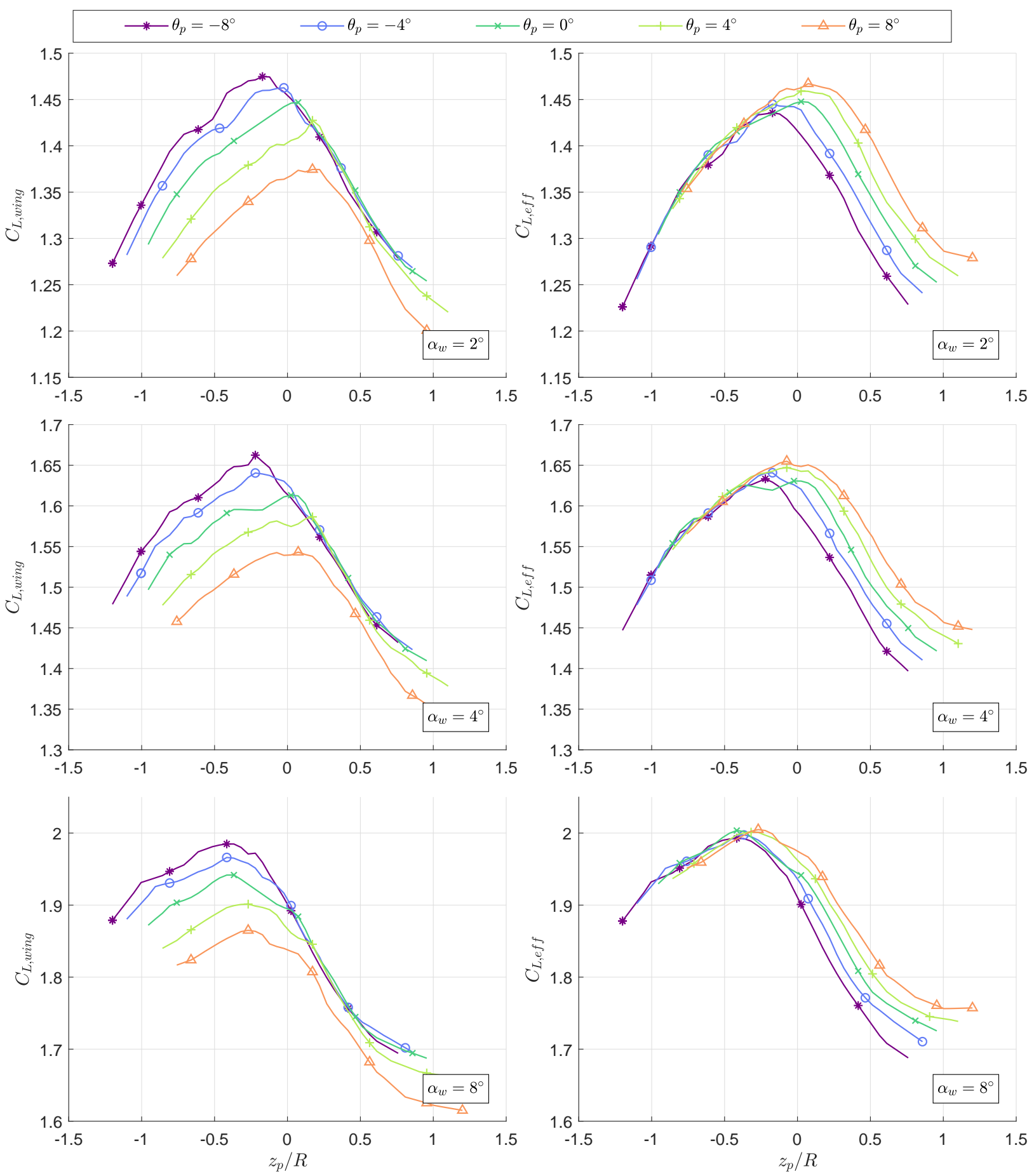

Fig. A.6 Lift coefficient vs. propeller height over a range of propeller inclinations at three angles of attack. $\delta_{f}=30^{\circ}, x_{p}=9^{\prime \prime}, D_{p}=10^{\prime \prime}$, and $J=0.4$. 

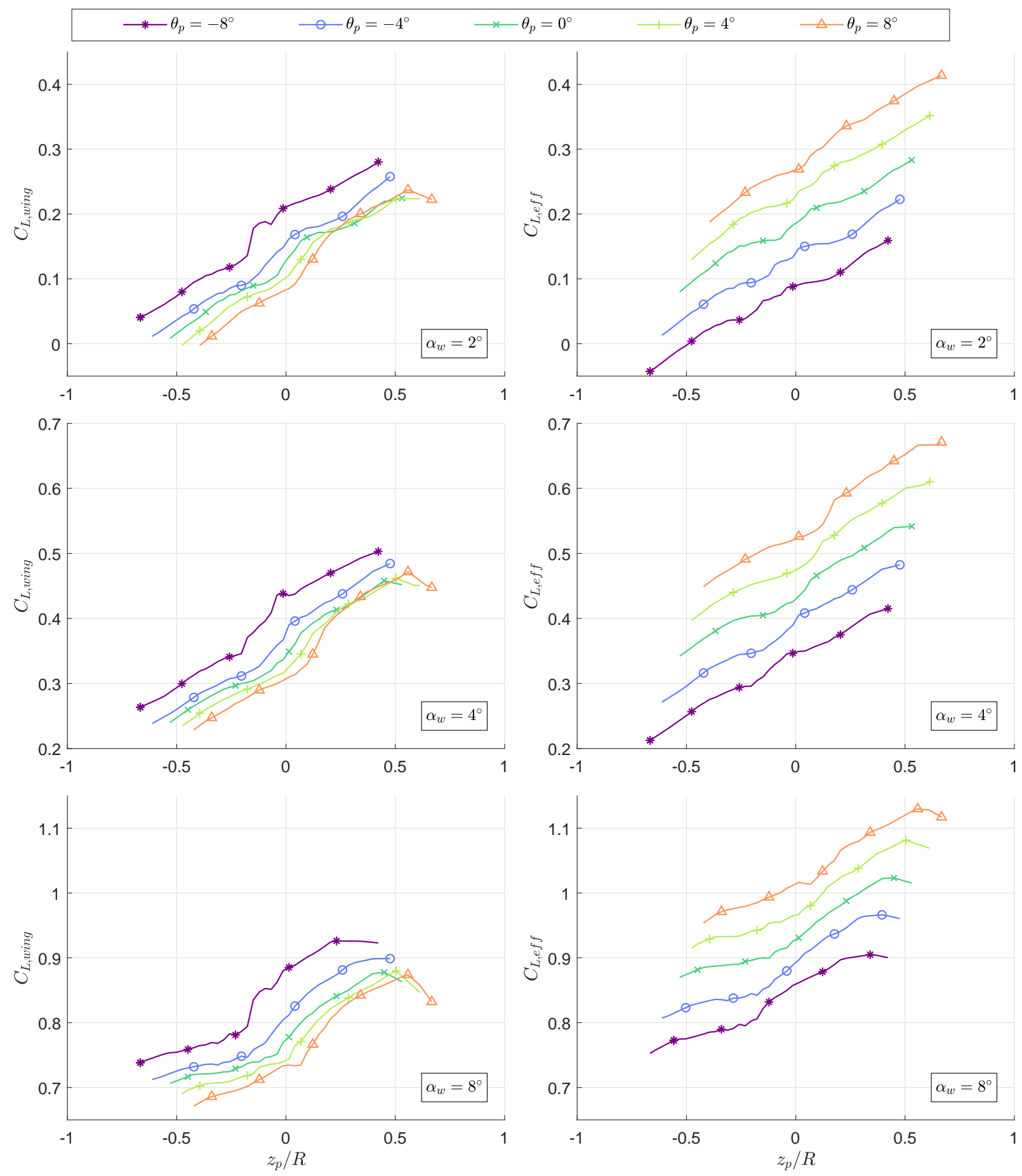

Fig. A.7 Lift coefficient vs. propeller height over a range of propeller inclinations at three angles of attack. $\delta_{f}=0^{\circ}, x_{p}=9^{\prime \prime}, D_{p}=18^{\prime \prime}$, and $J=0.4$. 

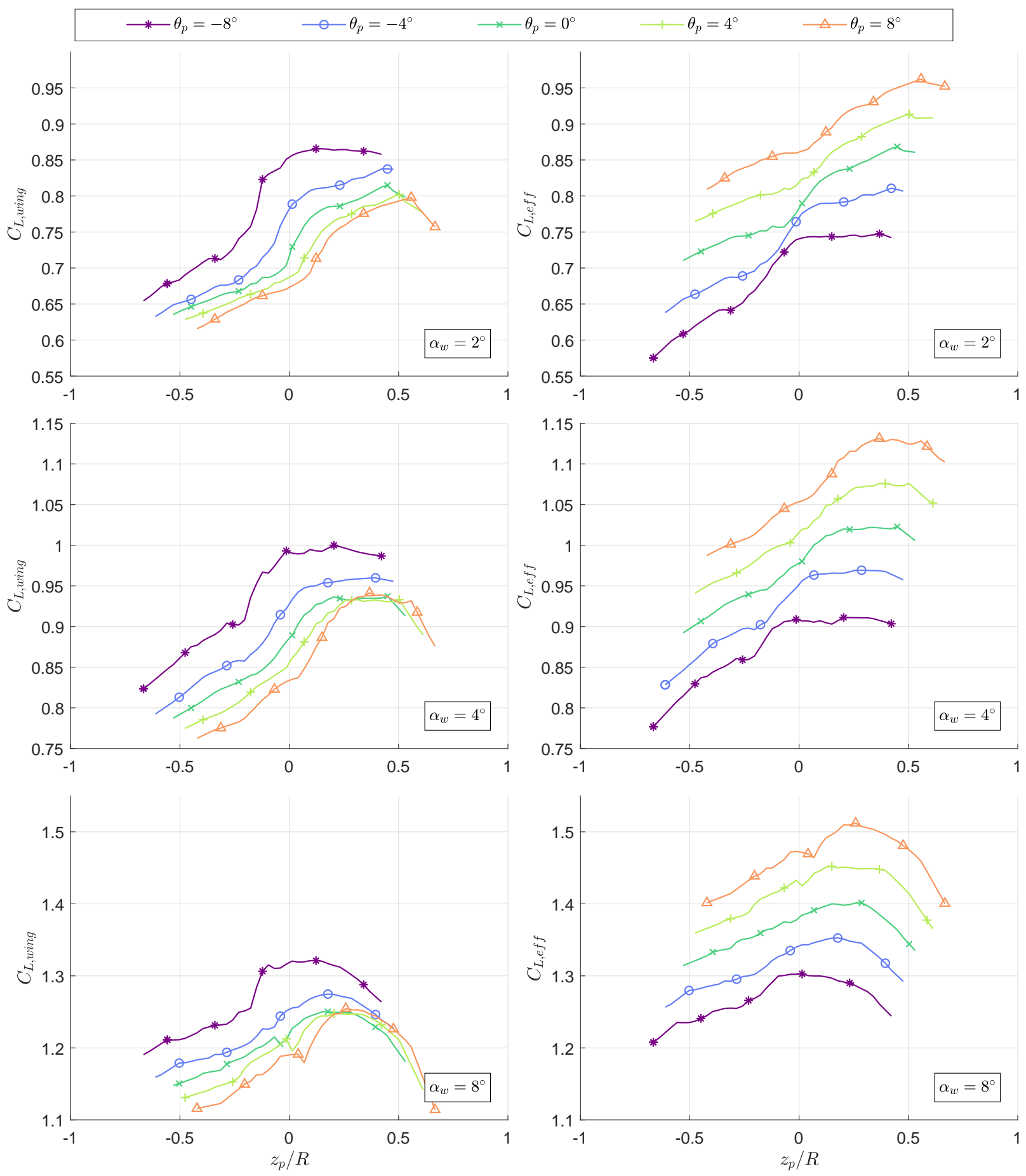

Fig. A.8 Lift coefficient vs. propeller height over a range of propeller inclinations at three angles of attack. $\delta_{f}=10^{\circ}, x_{p}=9^{\prime \prime}, D_{p}=18^{\prime \prime}$, and $J=0.4$. 

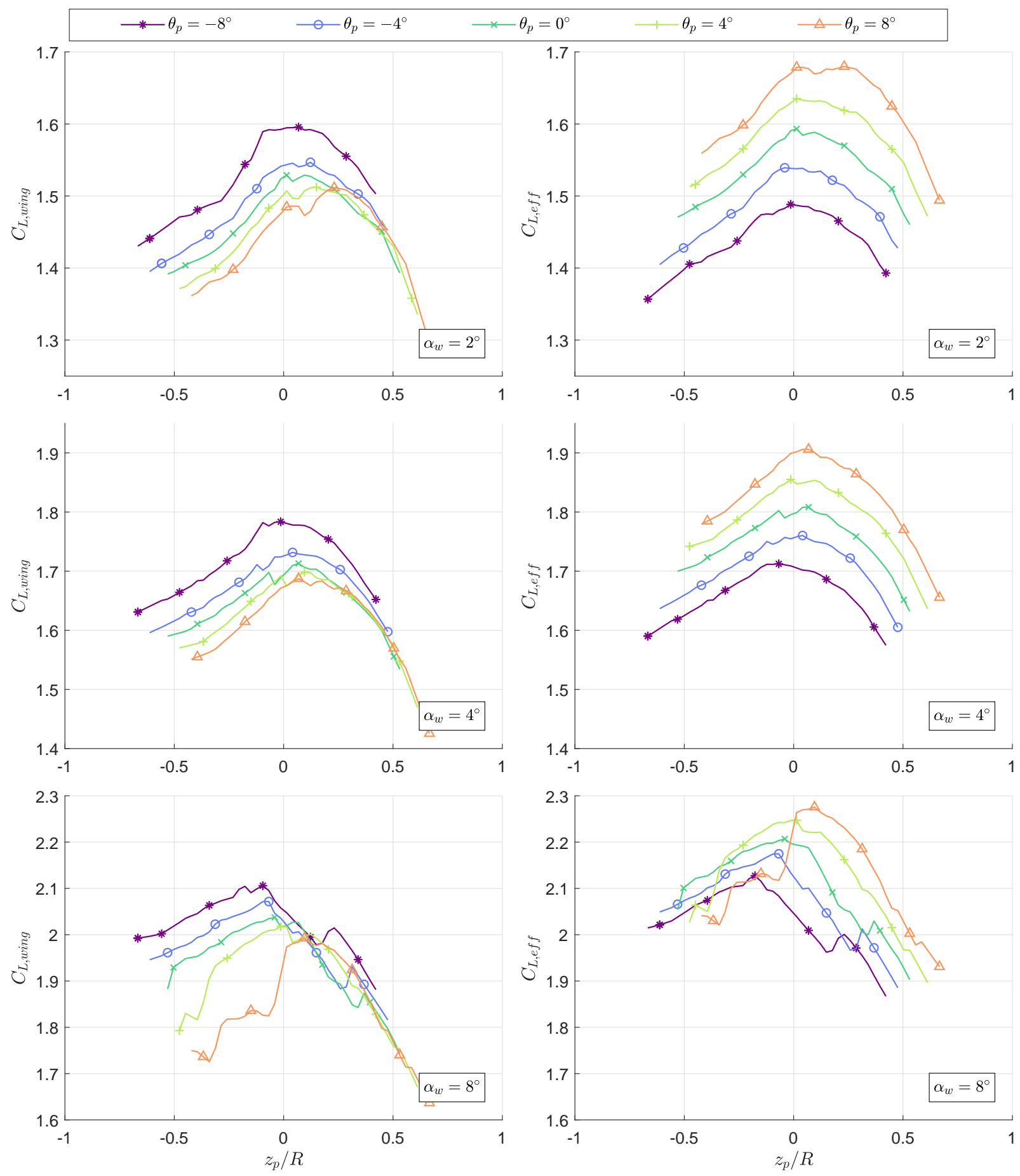

Fig. A.9 Lift coefficient vs. propeller height over a range of propeller inclinations at three angles of attack. $\delta_{f}=30^{\circ}, x_{p}=9^{\prime \prime}, D_{p}=18^{\prime \prime}$, and $J=0.4$. 

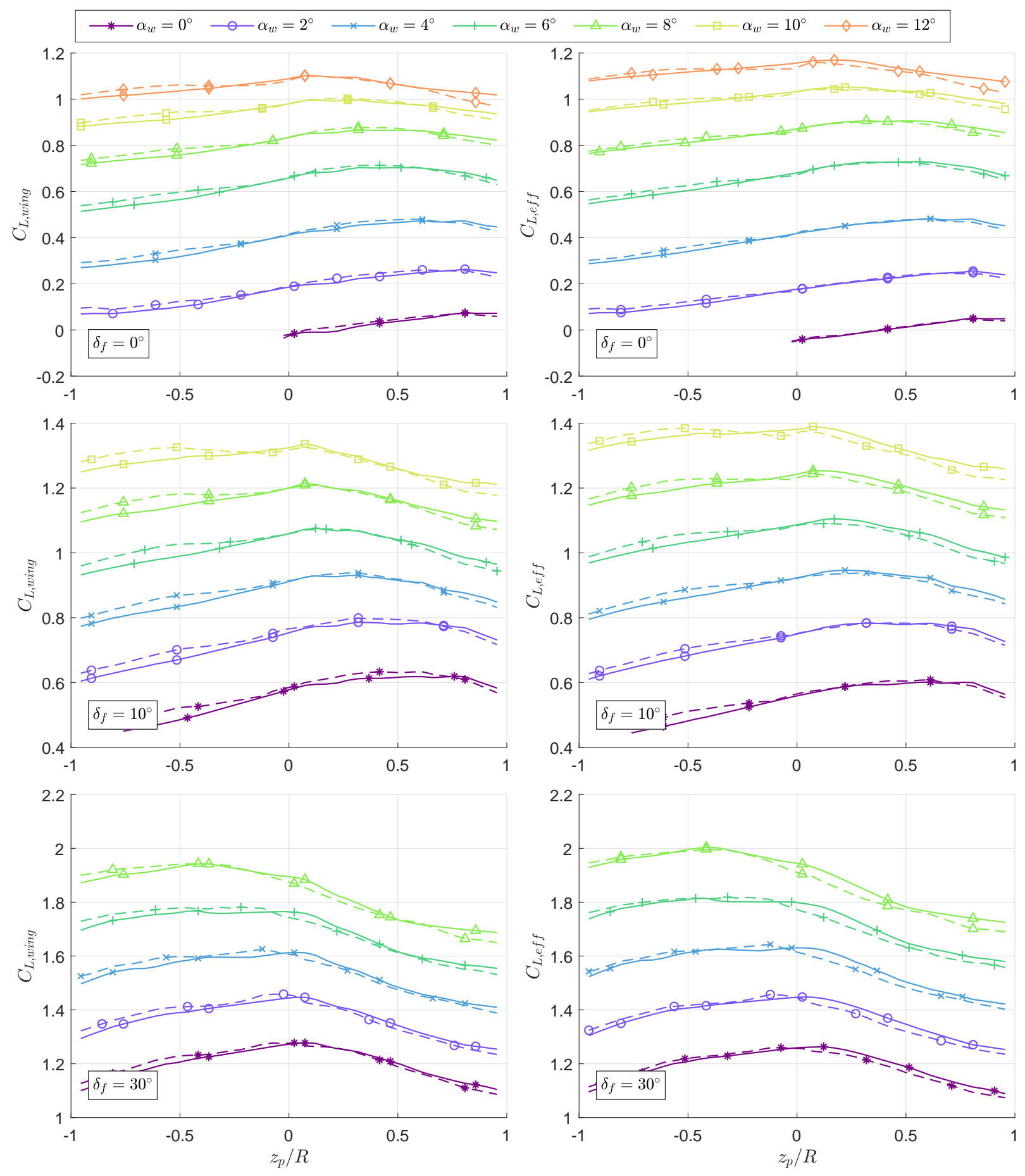

Fig. A.10 Effect of propeller offset on lift coefficient vs. propeller height. Solid lines represent $x_{p}=9$ " and dashed lines represent $x_{p}=11^{\prime \prime} . \theta_{p}=0^{\circ}, D_{p}=10^{\prime \prime}$, and $J=0.4$. 

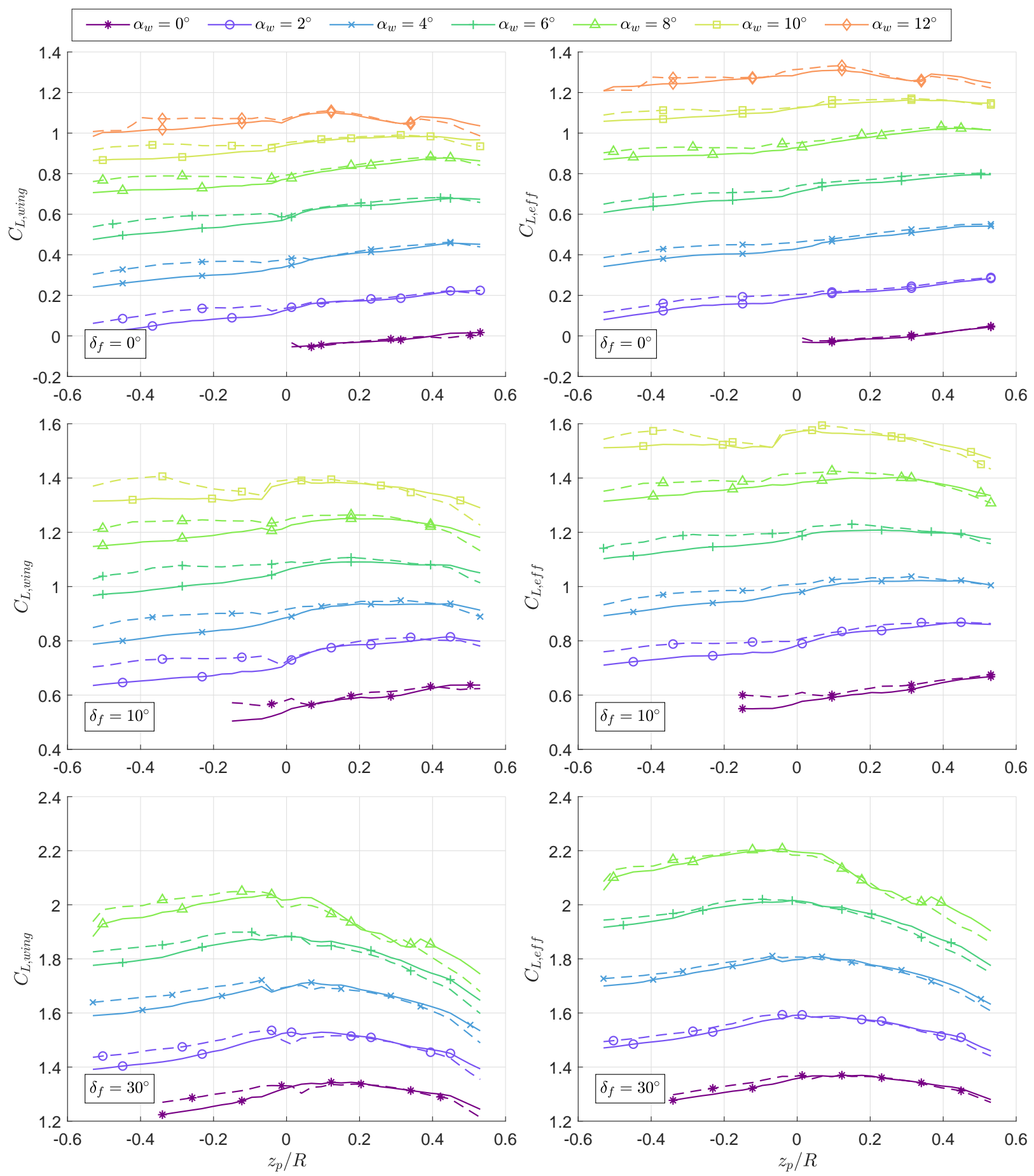

Fig. A.11 Effect of propeller offset on lift coefficient vs. propeller height. Solid lines represent $x_{p}=9$ " and dashed lines represent $x_{p}=11^{\prime \prime} . \theta_{p}=0^{\circ}, D_{p}=18^{\prime \prime}$, and $J=0.4$. 


\section{Acknowledgments}

This work was funded under the Transformational Tools and Technologies Project of the Transformative Aeronautics Concepts Program.

\section{References}

[1] Moore, M., "NASA Puffin Electric Tailsitter VTOL Concept," 10th AIAA Aviation Technology, Integration, and Operations (ATIO) Conference, 2010.

[2] Moore, M. D., and Goodrich, K. H., "High Speed Mobility through On-Demand Aviation," 2013 Aviation Technology, Integration, and Operations Conference, 2013.

[3] Moore, M. D., "Misconceptions of Electric Aircraft and their Emerging Aviation Markets," 52nd Aerospace Sciences Meeting, 2014.

[4] Fredericks, W. J., Moore, M. D., and Busan, R. C., "Benefits of Hybrid-Electric Propulsion to Achieve 4x Cruise Efficiency for a VTOL UAV," 2013 International Powered Lift Conference, 2013.

[5] Borer, N. K., Patterson, M. D., Viken, J. K., Moore, M. D., Bevirt, J., Stoll, A. M., and Gibson, A. R., "Design and Performance of the NASA SCEPTOR Distributed Electric Propulsion Flight Demonstrator," 16th AIAA Aviation Technology, Integration, and Operations Conference, 2016.

[6] Stoll, A. M., Stilson, E. V., Bevirt, J., and Pei, P. P., "Conceptual Design of the Joby S2 Electric VTOL PAV," 14th AIAA Aviation Technology, Integration, and Operations Conference, 2014.

[7] Hodgetts, R., "Successful test flight brings Lilium electric air taxis closer to reality," http://edition.cnn.com/2017/04/25/aviation/lilium-electric-vtol-jet/, 04 2017. URL http://edition.cnn.com/2017/04/ 25/aviation/lilium-electric-vtol-jet/, accessed: 2017-05-31.

[8] Warwick, G., "Aurora Tests eVTOL Air Taxi for Uber," http://awin.aviationweek.com/ArticlesStory.aspx?id=0e8bb3ff37c3-474d-aaa7-f6797e6ba641, 04 2017. URL http://awin .aviationweek. com/ArticlesStory .aspx?id=0e8bb3ff37c3-474d-aaa7-f6797e6ba641, accessed: 2017-05-31.

[9] Washington, G. W., "Inside Airbus A3's Vahana Electric VTOL," http://awin.aviationweek.com/ArticlesStory.aspx?id=ad82145228b1-4c44-b817-bf19942f3360, 05 2017. URL http://awin. aviationweek . com/ArticlesStory . aspx?id=ad82145228b1-4c44-b817-bf19942f3360 accessed: 2017-05-31.

[10] Patterson, M. D., “Conceptual Design of High-Lift Propeller Systems for Small Electric Aircraft,” Ph.D. thesis, Georgia Institute of Technology, 2016.

[11] Deere, K. A., Viken, J. K., Viken, S., Carter, M. B., Wiese, M., and Farr, N., "Computational Analysis of a Wing Designed for the X-57 Distributed Electric Propulsion Aircraft," 35th AIAA Applied Aerodynamics Conference, 2017.

[12] Deere, K. A., Viken, S. A., Carter, M. B., Viken, J. K., Derlaga, J. M., and Stoll, A. M., "Comparison of High-Fidelity Computational Tools for Wing Design of a Distributed Electric Propulsion Aircraft," Aviation Forum, AIAA, Denver, Colorado, 2017.

[13] Borer, N. K., Derlaga, J. M., Deere, K. A., Carter, M. B., Viken, S. A., Patterson, M. D., Litherland, B. L., and Stoll, A., "Comparison of Aero-Propulsive Performance Predictions for Distributed Propulsion Configurations," 55th AIAA Aerospace Sciences Meeting, 2017.

[14] Litherland, B. L., Patterson, M. D., Derlaga, J. M., and Borer, N. K., "A Method for Designing Conforming Folding Propellers," 17th AIAA Aviation Technology, Integration, and Operations Conference, 2017.

[15] Patterson, M. D., Derlaga, J. M., and Borer, N. K., "High-Lift Propeller System Configuration Selection for NASA's SCEPTOR Distributed Electric Propulsion Flight Demonstrator," 16th AIAA Aviation Technology, Integration, and Operations Conference, 2016.

[16] Gentry Jr, G. L., Takallu, M., and Applin, Z. T., "Aerodynamic Characteristics of a Propeller-Powered High-Lift Semispan Wing," Tech. rep., National Aeronautics and Space Administration Langley Research Center, 1994.

[17] Veldhuis, L. L. M., "Propeller Wing Aerodynamic Interference,” Ph.D. thesis, Delft University of Technology, 2005. 
[18] Brandt, J., and Selig, M., "Propeller Performance Data at Low Reynolds Numbers," 49th AIAA Aerospace Sciences Meeting including the New Horizons Forum and Aerospace Exposition, 2011.

[19] Brandt, J. B., Deters, R. W., Ananda, G. K., and Selig, M. S., "UIUC Propeller Data Site," http://mselig.ae.illinois.edu/props/propDB.html, 2017. URL http://m-selig. ae.illinois.edu/props/propDB.html accessed: 2017-05-31.

[20] Patterson, M. D., and Borer, N. K., "Approach Considerations in Aircraft with High-Lift Propeller Systems," 17th AIAA Aviation Technology, Integration, and Operations Conference, 2017. 